\title{
Alienação de universitárias vulneráveis: seis casos de emancipação
}

\author{
Ivar César Oliveira de Vasconcelos* \\ Universidade Católica de Brasília \\ Helen Tatiana dos Santos Lima** \\ Universidade Católica de Brasília \\ Ingrid Cristian da Silva Bezerra de Menez*** \\ Universidade Católica de Brasília
}

Resumo Jovens universitárias podem advir de comunidades vulneráveis, lugares onde faltam informações sobre direitos e oportunidades e, por outro lado, sobram informações sem sentido. Parte delas se aliena, pois, prioriza a busca de solução para problemas imediatos. Outra parte, supera o círculo vicioso da violência-exclusão-alienação. Como o conseguem? Como a educação superior contribui para isso? Um estudo de casos múltiplos, envolvendo seis jovens estudantes, revelou experiências sociais emancipadoras dessas mulheres. A autocrítica, em espaços abertos pela educação superior, mostrou-se elemento-chave na virada de rumo de suas vidas. As conclusões podem contribuir com a atuação didático -pedagógica de professores, inclusive para sua formação.

PALAVRAS-CHAVE: Violência-exclusão-alienação; Emancipação; Vulnerabilidade. 


\section{Alienation of vulnerable female university students: six emancipation cases}

Abstract Female young students may come from vulnerable communities, where information on their rights and opportunities is scarce, while the meaningless information abounds. Part of them gets alienated, as they prioritize searching for solutions to more immediate problems. The other part of them overcome the vicious circle of violence-exclusion-alienation. How can they do it? How does the higher education contribute to this? A multiple case study involving six young students revealed emancipatory social experiences of these women. Self-criticism, in open spaces through the higher education, has proved to be a key element in the turn of course of their lives. The conclusions of the present research may contribute to improve the didactic-pedagogical performance and formation of professors.

KEYWORDS: Violence-exclusion-alienation; Emancipation; Vulnerability.

\section{Introdução}

Em comunidades vulneráveis, moradores sofrem a falta de informações precisas sobre seus direitos e oportunidades. Em contrapartida, chegam-lhes informações que podem confundir, numa enorme e diversificada quantidade de estímulos e incentivos, nem sempre os melhores, reforçando a violência, exclusão e alienação. Este círculo vicioso se insere num mundo globalizado, com tendência à padronização de estilos de vida, relações sociais, linguagens e condutas, gerando uma espécie de cegueira quanto aos contextos de vida, e até das pessoas umas para as outras. Estabelece-se uma nuvem de invisibilidade que as deixa solitárias, ilegíveis, provavelmente, no risco de nem a si perceberem.

Nesse cenário e, intensamente nas mencionadas localidades, produz-se o falso discurso de respeito às diversidades individuais e coletivas. Falso porque, em meio ao acúmulo de informações/mensagens entre seus moradores, parece que tal discurso possui uma força que os deixa sem refletir sobre valores e projetos de vida, mantendo -os na estreita visão do dia a dia em sua faina pela sobrevivência. Ele alardeia o caráter humano das relações, mas, ao contrário, retira-o da roda da vida. Logo, um discurso violento. Geram-se violências que, com o passar do tempo, se naturalizam: falta de saneamento básico decente, pouca atenção de políticas públicas e muitas notícias midiáticas e bares com suas drogas. Um intrincado de violências que podem ser físicas, e de outros tipos, instaladas no corre-corre de seus moradores, em busca de direitos.

De modo peculiar, as mulheres dessas comunidades sofrem as consequências do mencionado círculo. Elas vivenciam desafios relacionados à questão cultural, exercendo papeis multifacetados - ora sendo mães, ora ajudando suas famílias de origem. Distancia-se o ideal de igualdade entre homens e mulheres. No domínio da educação, precipuamente a superior, os desafios vão do acesso à permanência nas instituições. 
Entretanto, a despeito desse quadro desanimador, parte dessas mulheres consegue superar o círculo vicioso da violência-exclusão-alienação, caracterizando a legítima emancipação, pois alargam a visão sobre sua realidade. De fato, por um lado, convivem com o paradoxo de estarem mergulhadas numa imensidão de informações que tanto podem contribuir com o seu desenvolvimento humano, como comprometer seu entendimento da realidade, pois as confundem; por outro lado, conseguem superar o mencionado círculo, mantendo-se distante dos processos de alienação. Até conseguem acessar, permanecer em instituições de educação superior e concluir seus cursos. De que forma o conseguem? Como superam os processos de alienação, aproveitando as oportunidades da educação superior? De que maneira esta pode contribuir com a emancipação delas?

Portanto, neste estudo, investigaram-se possíveis experiências de superação da violência e exclusão, utilizadas por mulheres de comunidades vulneráveis que ingressaram na educação superior, para descobrir como essas experiências se convertem em emancipação, inclusive, com o aproveitamento de oportunidades para elas oferecidas por esse nível de educação, a fim de entender meios de concretizar cada vez mais a conscientização dessas mulheres para a sua realidade de vida. Espera-se contribuir para uma reflexão sobre o problema e com soluções para localidades mergulhadas na infinidade de informações pouco claras e precisas sobre os diversos temas de interesse, inclusive, relativamente aos direitos à educação.

\section{As lógicas que dinamizam o circuito violência-exclusão-alie- nação}

Parece existir uma relação dialética a unir e dinamizar o circuito violência -exclusão-alienação em meio ao acúmulo de informações sem sentido para as vítimas desse circuito. Se hoje as sociedades multiculturais, multilinguísticas e multirácicas "se destroem e [se] constroem com lógicas que pouco têm a ver com as lógicas das sociedades que as precederam" (TAVARES, 1996, p. 13), isso ocorre porque as relações sociais do tempo atual são elaboradas assente em lógicas diferentes das que predominavam quando os papeis sociais eram definidos com maior clareza, inclusive, quanto à atuação dos detentores de poder. De fato, a análise da distribuição do poder no percurso histórico que vai da sociedade agrária à pós-industrial evidencia que essa distribuição deixa de estar centralizada entre os que detêm a terra, passa pelos capitalistas e chega a quem tem a informação (BELL, 1974).

Nesse mundo de papeis cada vez mais indefinidos, envolvendo quem tem e quem não poder de decisão sobre a vida da maioria das pessoas, essas novas lógicas podem estar na base de microssistemas de relações sociais, como, por exemplo, o mencionado circuito violência-exclusão-alienação. Assim, o acúmulo de informações sem sentido se configura como uma espécie de amálgama a vincular os componentes desse circuito. As violências do mundo lotado dessas informações encontram abertura e reforço em comunidades vulneráveis, irredutíveis às físicas, pois, indivíduos que buscam sobreviver, nessas localidades, frequentemente, pouco percebem que as experiências do dia a dia são repletas de agressões, efetivos rombos dos laços sociais, que, no limite, levam tais indivíduos à margem de sistemas sociais - crianças e adolescentes recebem 
mensagens advindas de bares, pontos de venda e consumo de drogas; entre os jovens, principalmente, o encantamento com as tecnologias da informação e comunicação e seus trilhões de bytes podem alienar; entre as meninas, há gravidez precoce; todos sofrem com a ausência de saneamento básico. Com efeito, são violências que excluem socialmente, pois "os fenômenos da exclusão, na sua ocorrência material ou simbólica, parecem bem derivar desses rombos do tecido social" (XIBERRAS, s/d, p. 239). São vários os modos de excluir populações as quais, nas mencionadas comunidades, continuam nutrindo a esperança de dias melhores. E, se há dificuldade para conceituar a violência, que se relaciona com diversos aspectos sociais (LIRA, 2016), também o conceito de exclusão social tem sido bastante estudado e procurado pelos autores (OLIVEIRA; OLIVEIRA, 2016). Numa palavra, o cotidiano da maioria dos vulneráveis é marcado pela vinculação entre violência e exclusão, nos termos aqui colocada. Tal vinculação abre portas para gerar ou ampliar a alienação entre as pessoas, pois, em sua labuta diária, o foco de atenção tende a ser a resolução de situações e problemas imediatos. Tais pessoas são as crianças, os homens e mulheres adultos, os idosos, independentemente das experiências sociais que elaboram e põem em marcha as suas vidas.

Assim, entende-se como circuito violência-exclusão-alienação a relação dialética entre as violências construídas como resultado da carga de informações inúteis e sem sentido sobre pessoas que buscam sobrevier; os processos de exclusão social, porquanto tais pessoas ficam presas em contextos desfavoráveis à maior ou menor participação cidadã, e a alienação decorrente da necessidade de focalizar a resolução de problemas imediatos.

Contudo, alguém poderia perguntar se ainda calha a referência à alienação num mundo repleto de informações, no qual 3,2 bilhões de pessoas se informam em tempo real pela internet, sendo que, dentre elas, 830 milhões são pessoas entre $15 \mathrm{e}$ 24 anos, o equivalente a 80\% da população jovem de 104 países (UIT, 2017). Afinal, ter informação não é estar incluído? Não é ter consciência das coisas? A resposta de longe é simples. Neste trabalho, admite-se que há exclusão e alienação, pois abundam informações, sem propósito, para os públicos finais. É claro que, há algum tempo, se percebe e se anuncia que a sociedade está lotada de informações. Se, por um lado, isso é bom, pois qualifica as pessoas pela enorme riqueza de dados, por outro, obriga-as a se manterem em eterna busca de sentido para elas.

Essa procura, definitivamente, participa do desenvolvimento dos sujeitos desde diversas perspectivas - psicológica, moral, ética, interpessoal, sociocultural -, o que implica considerar a formação de personalidades ao longo da vida no contexto de suas interações entre si em meio à dissociação de sistemas sociais. Portanto, pensar esse desenvolvimento envolve a complexa possibilidade de as experiências sociais dos indivíduos, tomadas em seu conjunto, contribuírem para fragmentar personalidades. Esse conjunto, no tempo atual, favorece a ideia de alienação enquanto capaz de promover essa fragmentação.

A noção de experiências sociais, formulada por Dubet (1994) para retratar o cenário em que se desenvolvem as relações sociais neste mundo chamado pós-moderno, contribui para o entendimento da alienação. Para o autor, elas são condutas 
coletivas e/ou individuais perpassadas pela heterogeneidade de seus princípios constitutivos e pela ação de cada indivíduo, responsável este por construir o sentido de suas ações no interior dessa heterogeneidade. Essa noção visa informar que os papéis, as posições sociais e culturais deixaram de ser componentes estáveis da ação dos indivíduos, pois as condutas se organizariam nessa heterogeneidade de princípios, culturais e sociais. Esta organização seria acompanhada por uma multiplicidade de orientações. Construídas segundo três lógicas de ação - integração, estratégia e subjetivação -, as experiências sociais podem ser identificadas, pois elas se inscrevem na objetividade do sistema (VASCONCELOS, 2015).

Em tal sistema, constatar o mergulho da ação humana em diversos princípios abre possibilidades de entender a nova alienação. Conforme Dubet (1994), a clássica ideia de alienação deu lugar à ideia de construção da experiência coletiva, não mais unificada pela dominação social. Ao contrário, esta tornaria as experiências sociais dispersas em territórios, podendo-se mencionar domínios como a cultura de massa, a exclusão econômica, o consumo, o preconceito e a participação política. Com isso, os indivíduos estariam a sofrer os impactos dos processos de desmoronamento de personalidades, valendo-se de lógicas de ação, inclusive, sem ser de sua autoria.

Em síntese, argumenta-se: 1) Comunidades vulneráveis são mais suscetíveis à contaminação por informações sem sentido, pois seus moradores se ocupam no dia a dia com problemas imediatos. 2) Essas pessoas, em geral, pouco percebem que suas experiências sociais estão permeadas de agressões que as distanciam de macro sistemas onde tais experiências são construídas. 3) $\mathrm{O}$ conjunto dessas experiências não se reúnem pela dominação social, mas, ao contrário, torna-se disperso por força dessa dominação. 4) A construção delas implica a destruição de personalidades, pois as lógicas subjacentes a essa destruição não são criadas por quem as utiliza.

As lógicas aqui discutidas parecem estar mais presentes entre mulheres vulneráveis, pois estas constroem suas experiências sociais (DUBET, 1994) em meio a desafios dispostos em questões culturais, tendo de exercer papeis multifacetados, de mãe e de suporte às suas famílias, frequentemente, em dificuldades econômicas, em desequilíbrio financeiro e desapercebidas da ideologia do consumo. As mulheres são 49,5\% (no Brasil, 50,8\%) da população mundial (ONU, 2017) e, no caso das vulneráveis, as alternativas de superação do mencionado circuito em muito ultrapassam o foco legal. Já existem no Brasil relevantes normatizações, como a chamada Lei Maria da Penha, promulgada, nos termos do art. 226 da Constituição Federal, para coibir e prevenir a violência doméstica e familiar contra a mulher; o Estatuto da Igualdade Racial e o regulamento do Sistema Nacional de Promoção da Igualdade Racial (BRASIL; 2006, 2010, 2013a). Contudo, entre elas, as violências continuam a excluir, retroalimentando a destruição de personalidades, isto é, fortalecendo a alienação. De todo modo, buscam alternativas para superar lógicas que vão da violência à alienação. 
Ivar César Oliveira de Vasconcelos - Helen Tatiana dos Santos Lima - Ingrid Cristian da

Silva Bezerra de Menez

\section{A superação das lógicas por meio da educação superior}

Tentativas de visualizar e compreender os processos de emancipação de mulheres, focalizando o acesso e a permanência na educação superior, precisam observar os contextos socioculturais nos quais essas pessoas se inserem. Em qualquer lugar do mundo, os contextos são diversificados e complexos, encobrindo o centro revelador da superação das lógicas subjacentes ao circuito violência-exclusão-alienação, o centro revelador do esforço pelo cumprimento de direitos humanos e sociais. Nessa perspectiva, o afã das mulheres em nome de sua emancipação tem sido destacado por historiadores, cabendo mencionar Bresciani (1992), em estudo a respeito de pessoas excluídas de direitos políticos na Europa e no Brasil. Além desses direitos, e o civil, a autora condiciona essa emancipação à conquista de instrução. Certamente, não a instrução voltada para formar o espírito ilustrado, mas aquela que enfrenta a cultura transplantada, numa escola não mais utilizada para fazer comunicados, e sim para possibilitar a inovação cultural (ROMANELLI, 2003; TEIXEIRA, 1976). No caso brasileiro, esses contextos incluem mulheres de comunidades vulneráveis, que, a seu modo, se lançam em desafios com o intuito de superar tais lógicas.

Esses desafios têm suas singularidades no âmbito da educação. Uma retrospectiva sobre a trajetória da mulher que acessa a educação formal evidencia vitórias circunscritas à busca por direitos sociais, inclusive, para contrapor o machismo, o preconceito e o descaso. Se os avanços sociais das mulheres, relacionados à educação como um todo, têm sido graduais, com limitações e diferenciações (BLAY; CONCEIÇÃO, 1991; HAHNER, 2003; QUEIROZ, 2000), no específico domínio da educação superior, a busca pelo êxito se identifica não apenas no tocante ao acesso, ampliando-se à permanência em instituições autorizadas.

Segundo o Relatório Global de Monitoramento da Educação 2017/2018, publicado pela Unesco (ONU, 2017), em geral, as mulheres têm contribuído mais do que os homens para o aumento de matrículas na educação superior, em todas as regiões do mundo, exceto na África Subsaariana (seria mera coincidência com a questão da vulnerabilidade discutida neste trabalho?). O Relatório informa ainda que, em diversos países, as mulheres ultrapassam os homens diplomados, em termos quantitativos, mas não o conseguem quando o campo formativo é o das ciências, tecnologias, engenharia e matemática, significando isso que os desafios delas ultrapassam o drama do acesso à educação superior. Com efeito, já se constatou que, desde antes desse ingresso, mulheres enfrentam desafios que refletem nos cursos mais frequentados por elas (PINTO; CARVALHO; RABAY, 2014), prosseguindo até a sua conclusão. Destacam-se obstáculos no interior das instituições afetos às divisões de ordem social, à tríplice jornada, aos preconceitos de raça e gênero e assim por diante, já caracterizadas suas vítimas como os excluídos do interior (BOURDIEU; CHAMPAGNE, 2015). Apontam nessa direção as informações do Fundo de Populações das Nações Unidas (UNFPA; 2013; 2016) sobre a maternidade precoce e seus graves impactos sobre as meninas em termos de educação, saúde e oportunidades de emprego, bem como os dados do Instituto Brasileiro de Geografia e Estatística (IBGE, 2000) atinentes à responsabilidade assumida pelas mulheres de sustentar suas famílias. Problemas esses potencializados em comunidades vulneráveis! 
À vista desses desafios concretos, até de sobrevivência, a superação dos processos que alienam ocorrerá se houver uma educação emancipadora. Nem sempre os ambientes educacionais constituem processos emancipatórios, como se discute logo à frente neste trabalho - principalmente com as finalizações de Adorno (1995) sobre o assunto. Como a educação superior pode contribuir com essa superação quando for o caso de mulheres vulneráveis? Entre os brasileiros, as inúmeras dificuldades desse nível de ensino tangenciam a urgente questão da sensibilidade individual para o problema da alienação. Espera-se que os envolvidos com a educação superior se comprometam com o desenvolvimento humano de pessoas que, a duras penas, chegam à universidade. Está em jogo a dignidade humana, alcançada efetivamente se professores e demais membros dessa instituição entenderem que ser digno, em termos humanos, é não ser alienado; é ser consciente da realidade. Para Morais (2011, p. 170), "ainda é tempo de que as pessoas [leia-se: os membros da escola como um todo] disponham-se a esforços, cultivando a grandeza de respeitar a intrínseca dignidade dos seres humanos em formação [incluam-se: estudantes mulheres de comunidades vulneráveis]". Realmente, lembrando Freire (2016, p. 62), o momento do qual participa qualquer geração de homens e mulheres "revela marcas antigas que envolvem compreensões da realidade, interesses de grupos, de classes, preconceitos...", perdurando no clima cultural características da atualidade concreta. $\mathrm{O}$ que, no limite e, presente as explicações freireanas, justificaria a indignação de quem zela pelo respeito à dignidade humana.

Entretanto, apenas a sensibilidade é insuficiente. Torna-se necessário compreender o que é educar para a emancipação em conexão com o termo formar. Inicialmente, a escola propõe a si contribuir com a formação voltada para a aquisição de qualidades sociais, emocionais e intelectuais. Por um lado, formar, igual à Paideia grega (JAEGER, 2001), Paideia moderna (ADORNO, 1995; ROUSSEAU, [1762], 2017) ou Bildung, conforme a proposta humboldtiana (FREITAG, 2001), se refere à busca da concretização da imagem de ser humano elaborada à luz de um tempo históricosocial-cultural. Nesse caso, os caminhos da emancipação passariam por vastas áreas do saber humano, presente essa imagem. Por outro lado, para Adorno (1995, p. 141), conceber uma imagem humana ideal se constitui em autoritarismo, pelo que se imporia a educação que vai de fora para dentro do indivíduo. Para o autor, educar não é o ato de modelar as pessoas a partir de seu exterior, nem a mera transmissão de conhecimentos, e sim a produção de uma consciência.

De fato, pressupondo-se que emancipar depende da formação, essa ação se refere aos contextos históricos, culturais e com a variedade de profissões, bem como à educação. Enquanto processo de construção da consciência crítica, por exemplo, a emancipação condiciona-se ao deslocamento do conceito atribuído ao ato formativo, para além da área pedagógica (FREITAG, 2001). Por isso mesmo, para Adorno (1995), se o verdadeiro ato educativo toma os indivíduos não como entidades solitárias, e sim como seres sociais, educar para a emancipação significa promover o aprendizado que rearticula o presente, possibilitando essa rearticulação com base em experiências sociais no nível individual.

O autor desenvolve esses estudos ao constatar a separação dos grandes sistemas de mundo. Entendeu que as esferas-macro da sociedade, a exemplo de instituições 
Ivar César Oliveira de Vasconcelos - Helen Tatiana dos Santos Lima - Ingrid Cristian da Silva Bezerra de Menez

como a escola, se mantinham lutando num campo de forças para equilibrar as relações de poder. Uma luta que desequilibra essas esferas, dissociando-as; destroem-se valores humanos, impedindo o desenvolvimento sociocultural das pessoas. Tal destruição advém de conglomerados de poder que, por sua vez, se apoiam na indústria cultural. Esta, embora as diferentes interpretações a seu respeito, se incumbe, dentre outras coisas, de alienar as pessoas, pois reforça normas não discutidas, impulsionando o conformismo social. Seguramente, isso reflete na escola.

Por último e não menos importante, cabe dizer: nem só sensibilidade, nem só entendimento, e sim, também, ação! No plano da atuação didático-pedagógica, para Stavracas e Esteban Rojo (2013, p. 167), ao educador cabe a leitura de cenários nas entrelinhas, isto é, deve ler aquilo que se esconde por trás da estrutura visível de seu trabalho, os parâmetros curriculares, os livros didáticos, dentre outros. De acordo com os autores, "ao fazer isso, o educador possibilitará aos seus discentes uma consciência crítica e reflexiva, permeada pela liberdade que se conquista por meio do esclarecimento".

Tomando essas informações como referência, efetivamente, este trabalho busca verificar, da perspectiva de mulheres vulneráveis que superaram as lógicas da violência e exclusão, o quanto a educação superior que vivenciam abre espaços para a sua emancipação.

\section{Incursionando a realidade}

Realizou-se uma pesquisa qualitativa-exploratória, configurada como estudo de casos múltiplos holístico (YIN, 2010) em que este oscila entre ser do tipo intrínseco e instrumental (STAKE, 2016), pois, valorizam-se, respectivamente, as experiências das participantes em seus contextos de vida e a questão finalística da pesquisa, qual seja, como essas participantes superam os processos de alienação, aproveitando as oportunidades da educação superior? Assim, a pesquisa se circunscreve a dois posicionamentos epistemológicos, indo de uma concepção que assume o rigor em investigações científicas a outra mais flexível.

Com efeito, baseia-se em Merriam (1998), com sua síntese entre as ideias tendentes ao positivismo presentes em Yin (2010) e as ideias existencialistas-construtivistas presentes em Stake (2016). De acordo com a autora, "o caso é uma coisa, uma entidade única, uma unidade cujas fronteiras são claramente limitadas [e o estudo de caso a análise de um fenômeno, podendo ser, por exemplo], uma instituição, um processo ou uma unidade social" (VASCONCELOS, 2017, p. 67). Desse modo, sem definir a priori um corpus discursivo para apoiar a análise dos dados (CARDOSO, 2004), buscaram-se modos diferentes de inserção a uma realidade construída em contextos sociais, atuais e difusos aptos à observação e à análise livre de elos epistemológicos.

Tal realidade se constituiu de três instituições de educação superior do Distrito Federal, particulares, com seis estudantes jovens (BRASIL, 2013b), sendo uma universidade (1 aluna), um instituto superior de educação (duas alunas) e um centro universitário (três alunas). Essas estudantes foram escolhidas com apoio em informa- 
ções obtidas por estes autores, antes da pesquisa, por demonstrarem atitude de superar a alienação, bem como a condição de vulneráveis. Portanto, em primeiro lugar, consideraram-se características das participantes (ver Quadro 1), e não das instituições - organização acadêmica ou categoria administrativa - ou dos cursos.

Quadro 1 - Informações sobre as participantes

\begin{tabular}{|c|c|c|l|c|}
\hline No. & Identificação & Idade & Organização acadêmica & Curso \\
\hline 1 & M1 & 29 & Instituto & Pedagogia \\
\hline 2 & M2 & 27 & Instituto & Pedagogia \\
\hline 3 & M3 & 22 & Universidade & Administração \\
\hline 4 & M4 & 23 & Centro Universitário & Pedagogia \\
\hline 5 & M5 & 29 & Centro Universitário & Pedagogia \\
\hline 6 & M6 & 29 & Centro Universitário & Pedagogia \\
\hline
\end{tabular}

Legenda: M1, M2... M6: Mulher 1, Mulher 2... Mulher 6. Fonte: Elaboração dos autores (2017)

Utilizou-se o relato de vida (BERTAUX, 2005), técnica de entrevista coadunável com o tipo da pesquisa assumida. No total, os relatos duraram 140 minutos, tendo iniciado com as seguintes introdução e perguntas:

Sofrendo violência e exclusão, parte de mulheres em situação de vulnerabilidade perdem a visão do todo social em que se encontram, pois em sua luta diária, buscam resolver problemas imediatos. Muitas se alienam, pois assumem diversos papeis sociais, como o de mãe e de suporte às suas famílias, enfrentando o machismo, o preconceito e o descaso. Ainda assim, parte delas consegue chegar à universidade. Sabendo da sua luta para chegar à educação superior e de algumas de suas experiências na sua comunidade, gostaria de ouvi-la: Como você e outras mulheres conseguem superar a violência, a exclusão e a alienação? Como conseguem ingressar e permanecer em instituições de ensino superior? Como a educação superior contribui para sua emancipação?

As gravações proporcionaram o material que, na sequência, foi submetido à análise de conteúdo (BARDIN, 2009), sendo cada relato um evento pontual e significativo do processo de vida individual das participantes. Realizou-se um cross-case, caracterizando um estudo de casos múltiplos.

\section{Os desafios do ingresso e permanência na educação supe- rior}

Os afazeres diários da mulher moderna encontram uma fiel representação no poema a seguir. Sua autora, que não concluiu o ensino fundamental, mostrou-se 
ferrenha defensora e praticante dos direitos da mulher no século XX. Neste seu escrito, vale o registro sobre a condição da mulher dividida em tempos ditos civilizados: "A mulher, não mãe, maternidade. Operária. Funcionária. Gerente gerenciando, computando perdas e ganhos alheios, igualando, superando, vitoriosas, tumultuadas. A neurose vai se alargando"(CORALINA, 2014, p. 224).

Um dos quintais dessa neurose pode ser o mundo das comunidades vulneráveis, com suas mulheres em correria, inclusive para estudar na escola formal. Os relatos das jovens universitárias que participaram da pesquisa evidenciaram o nervosismo dos contextos sociais, com causas, não plenamente demonstráveis, mas passíveis de serem constatadas, incluindo os âmbitos da família e do trabalho, sendo tais causas ladeadas e configuradas por itens sócio-culturais-econômicos que fazem parte de corredores e salas de aula das instituições de ensino superior. De acordo com a pesquisa realizada, a condição dessas mulheres cabe na metáfora de malabaristas, pois, precisam saber lidar com esses contextos, além de empenhar-se contra a frequente tendência à fuga social, afastamento, resignação.

Do acesso à permanência na educação superior, as violências, físicas ou simbólicas, seguidas de exclusão social, participam dos mencionados contextos. Sendo dessa maneira, é violência quando a família da M1, ao tê-la em casa grávida aos quatorze anos, não a apoiou em seu intuito de continuar os estudos no ensino médio. O pai da criança, agora membro de sua família, deixou a escola, mas ela insistiu e lá permaneceu. Já na educação superior, levava o bebê para a sala de aula, onde os dois dormiam de cansaço. No final do curso, em 2014, seu filho sofreu paralisia - sequer ela foi à festa de formatura, paga com sacrifício. Seu marido desistiu de estudar, ela deixou de suportar os desentendimentos com ele. Abandonaram-se. Segundo informou, "outras colegas desistem porque os maridos espancam, brigam".

Já a M2, embora tenha tido o apoio do marido, sofreu também a violência do contexto: "Assim que terminei o ensino médio, logo eu casei; e já tive minha filha. E a faculdade ficou de lado; mas, sempre ali a sementinha na cabeça”. Ao referir-se à educação superior, queixou-se do desconhecimento com respeito às tecnologias, da carestia dos livros e do alto valor das passagens de ônibus. Às vezes, a violência da família se revela como pressão para trabalhar em vez de estudar. A M3, por exemplo, apesar de ter escapado da gravidez precoce, sofreu pressão da mãe e avó para que estudasse com vistas à aprovação em concurso público, em vez de seguir pela educação superior após finalizar o ensino médio.

Das outras três participantes, a M4 lamentou também a pressão da família, em especial, acerca da permanência na educação superior: "As pessoas me olham e colocam uma responsabilidade muito grande sobre mim. Pessoas da minha cidade me cobram; a família de meu namorado me cobra. Será que consigo? Às vezes, isso me trava". Queixou-se da cobrança sofrida até pelos modos de se expressar. "E isso é sufocante". Ela sente uma desorganização em seus pensamentos.

Esses desafios familiares andam juntos, nos casos estudados, com questões sociais, culturais, econômicas, inclusive, concernentes ao mundo do trabalho. Somente 
uma das mulheres não recorreu a financiamentos para estudar, como o fizeram as demais, ao Fundo de Financiamento Estudantil (FIES) (3 estudantes) e a bolsas de 50\% da instituição ( 2 estudantes). A que não recorreu se valeu de ganhos de trabalho informal desenvolvido na comunidade onde mora. A propósito, todas disseram trabalhar duro desde cedo, sendo babá (creche ou em casas de vizinhas), faxineira, telemarketing, com sacrifícios persistentes ao longo do curso. No tocante às dificuldades com as tecnologias, pelo menos a M2 explicou que "quando a gente chega do ensino médio [...] não é nada daquilo que a gente sonha [para a educação superior]". Ela se referiu, principalmente, quanto à tecnologia, tendo pensado em pagar para alguém realizar suas atividades escolares, mas as colegas a ajudaram. De qualquer maneira, reforçando a ambiguidade ética presente há séculos no contexto cultural brasileiro (DAMATTA, 2004), para ela, "esses desafios são assim mesmo; a gente vai ter que ir superando, dando o jeitinho brasileiro, porque, senão, a gente não dá conta”.

As dificuldades também passam por algum preconceito sentido, alimentado pelo desconhecimento de colegas na sala de aula sobre as condições de vida dessas mulheres. Isso evidenciou o relato de M3 sobre uma pergunta de colega de turma, durante uma conversa: "M3, onde você mora?" Ao que ela respondeu: Em Ceilândia. "Em Ceilândia?” Admiraram-se as outras colegas, presentes à conversação.

Todo mundo falou: 'Você sai da Ceilândia [casa] pra ir pra Asa Sul [universidade] e depois pra o Núcleo Bandeirantes [trabalho]? Não acha contramão, não?' Eu falei: 'Não é o que eu quero?' Eu sentava no fundo [da sala] sozinha; ninguém falava comigo na sala [...], porque o povo na faculdade, é quem? Que o pai tem condição.. não tem que correr atrás de nada... só tem que estudar... não precisa trabalhar.

Para completar o cenário de correria e dispersão, M3 reclamou da exigência de professores ao estágio curricular, "para ganhar 400 reais", portanto, menos do que ganha em seu atual emprego. Narrou ser impossível abandonar este, pois seu pai "não tá trabalhando, [a] mãe é auxiliar de serviços gerais e vira e mexe, parentes vão para cá; minha prima foi embora ontem, tendo ficado um mês aqui; teve gêmeos, com marido e dois filhos". É, de fato, o quadro semelhante às vivências de Bernadette, a personagem em De Gaulejac (2008), a qual, sentada no fundo da sala de aula, alimentando sonhos irradiados de uma fotonovela, se torna crítica e se revolta. Portanto, esses contextos são violentos e contribuem para a exclusão social.

Tais evidências, geradas a partir do percurso indutivo, possibilitaram relacionar aspectos sociais que, igual aos nós de uma rede, parecem difundir seus efeitos sobre o dia a dia dessas mulheres, dinamizando e fortalecendo contextos aptos a mantê-las presas no circuito violência-exclusão, o qual se estende para finalizar com a alienação (ver Quadro 2). 
Ivar César Oliveira de Vasconcelos - Helen Tatiana dos Santos Lima - Ingrid Cristian da Silva Bezerra de Menez

Quadro 2 - Contextos de violência e exclusão no ingresso e permanência na educação superior

\begin{tabular}{|l|l|l|l|}
\hline Família & Trabalho & $\begin{array}{l}\text { Situação sócio- } \\
\text { cultural-econômica }\end{array}$ & Vida acadêmica \\
\hline $\begin{array}{l}\text { A gravidez precoce. } \\
\text { Pressão familiar } \\
\text { para que priorize o } \\
\text { trabalho e não os } \\
\text { estudos. Cobrança } \\
\text { da família para que } \\
\text { os estudos deem } \\
\text { resultados, como um } \\
\text { bom emprego. }\end{array}$ & $\begin{array}{l}\text { Cedo na vida, o } \\
\text { trabalho informal, } \\
\text { como, por exemplo, } \\
\text { babá; formal, como } \\
\text { faxineira e operadora } \\
\text { de telemarketing. }\end{array}$ & $\begin{array}{l}\text { Desigualdade } \\
\text { sociocultural, entre } \\
\text { estudantes, como } \\
\text { motivo para o } \\
\text { isolamento sofrido } \\
\text { na sala de aula. }\end{array}$ & $\begin{array}{l}\text { Preconceito em } \\
\text { função do lugar } \\
\text { onde mora. }\end{array}$ \\
$\begin{array}{l}\text { Exigência de estágio } \\
\text { supervisionado } \\
\text { em detrimento de } \\
\text { trabalho remunerado. }\end{array}$ \\
\hline
\end{tabular}

Fonte: Elaboração dos autores (2017)

Os problemas enumerados no Quadro 2 parecem se vincular diretamente com a luta pela sobrevivência. Portanto, desenvolvem-se em meio a necessidades imediatas. $\mathrm{Na}$ esfera familiar, por exemplo, essas mulheres se apoiam em mães e maridos, embora, inicialmente, tenham sofrido pressão para trabalhar em vez de apoio para estudar. A M5, por exemplo, só conseguiu continuar na educação superior depois de mudar-se para perto da mãe. Outra, ao se comparar com membros da família, reconheceu ser impossível adiar o ingresso e permanência na educação superior, pois "chega uma idade na vida em que não se tem mais 'pique' para estudar, nem vontade de estudar" (M6).

Outras ainda se percebem dotadas de características adquiridas na família favoráveis à superação: "Observo que, desde minha adolescência, sempre tive um potencial para falar, representar a juventude" (M4). Neste caso, a estudante encontra na própria história a explicação por que terá saído da exclusão social. Tal perfil, inclusive, a ajudou a superar o isolamento sofrido na sala de aula ao mudar de turno. Ao ir da manhã para a noite, relatou, ela se sentiu um pouco excluída pela turma, mas, depois, se sobressaiu, tendo sido aceita por ela.

De todo modo, ficou evidenciado pela pesquisa que elas se superam ao encontrar sentido em suas ações. Em meio às dificuldades, se movimentam entre o que entendem ser correto fazer, pelos próprios interesses e por projetos de vida. Como indica o poema de Coralina (2014), mulheres desse tipo são capazes de se superar, porém, diga-se, em meio às cegas, podendo alienar-se, pois constroem suas experiências sociais impulsionadas por necessidades imediatas. Tendo conseguido acessar e permanecer na educação superior, de que modo elas se emancipam, aproveitando as oportunidades oferecidas por esse nível de ensino? Em tempos da chamada democratização, com o discurso de que a ação educativa se volta para a emancipação social dos alunos e não para a sua alienação, quais experiências são efetivamente emancipadoras? Afinal, como lembram Honorato e Heringer (2015, p. 26) sobre a massificação e diversificação do 
sistema escolar, alunos que acessam juntos em igual ano, igual curso de graduação, igual instituição, "podem construir uma experiência de formação e elaborar estratégias de permanência e conclusão dos estudos, além de significados à educação superior e à inserção profissional, completamente diferentes".

\section{Experiências sociais emancipadoras: os espaços oferecidos pela educa- ção superior}

As experiências sociais evidenciadas neste artigo se caracterizam como emancipadoras porque implicam, do lado das participantes, a capacidade de encontrar sentido nelas e, do lado de educadores, a sensibilidade para o desenvolvimento humano, o entendimento do termo educar para a emancipação e a ação didático-pedagógica favorável à concretização de consciência crítico-reflexiva. Considerando que os relatos foram apenas das estudantes, e não de professores, as evidências se situam no mundo delas, mas apontando para os espaços favoráveis à construção de experiências no âmbito da educação superior.

Entende-se que o mencionado sentido é encontrado apenas em contextos com informações honestas, bem-intencionadas, significativas. Ele ocorre quando as participantes percebem a iminência de violências e exclusão e, simultaneamente, se conscientizam de que as próprias experiências se dispersam em pontos de poder. Desse modo, apresentam-se, a seguir, narrativas das estudantes reveladoras de sua convicção de que, apesar dessa dispersão, ainda é possível internalizar e expressar seus valores, exercer influência sobre os outros e se empenhar em modelos culturais construídos por elas com base em críticas cognitivas e/ou normativas (DUBET, 1994).

Assim, entre elas, vale a pena estudar para mudar de vida. Essa mudança significa, para elas, sair do lugar comum habitado pela maioria das pessoas com quem convivem, como expressou M1: "Vi que podia conquistar outras coisas, não ficar na mesmice". Com a educação superior, ela pôde tomar decisões na vida, como "largar o marido que não quis mais estudar", fazer uma pós-graduação ou, ainda, com os estudos, melhorar o vocabulário e mudar a visão sobre as crianças. Enfim, "você se torna outra pessoa". Igualmente, para M4, o curso de Pedagogia ajudou a lidar com as crianças, antes, uma dificuldade para ela: "Eu era muito impaciente [...] e, com o curso, eu vi que não é tão simples lidar com elas". Igualmente, M6 se tornou "uma pessoa mais solidária, aberta a ajudar o próximo". Mudar de vida é ainda para elas aprender a lidar com o preconceito, mesmo na família, sendo um aprendizado favorecido pela educação superior, como exemplifica o relato de M5:

Eu tenho um irmão que gostava muito de brincar de bonecas; eu cresci ouvindo minha mãe, minha família, falar: 'Isso não pode, isso é coisa de mulher'. Diziam: 'Você nasceu homem no corpo de menina e a M5 nasceu menino no corpo de menina'. Eu acho que eu tinha um certo tipo de preconceito com ele [...]. Depois que entrei na universidade, cheguei numa bendita disciplina, me fez pensar muito e isso foi acabando.

Esses relatos denotam o espaço aberto pelas instituições superiores, onde estudam as participantes, direcionado para a construção de valores. Algo ocorre nessas 
escolas favorável à percepção de que é primordial cuidar dos modos de comunicar-se, ter paciência com crianças, ser solidário e respeitar as diferenças individuais. Sem essas contribuições também seria impossível às jovens a percepção de que estavam concretizando objetivos de vida, interesses.

Nessa perspectiva, M3 informou que, com a educação superior, passou a ser alguém mais centralizada, com mais foco. Como declarou, "antes eu não queria nem fazer faculdade; depois [...] vi que não dá para não fazer faculdade”. Paralelamente, M2 explicou que o processo de descoberta de "um novo mundo, novas pessoas, novos olhares, visões diferenciadas", proporcionado pela educação superior, foi difícil, mas "uma maravilha". Por sua vez, M4 relatou: "Consegui o que planejei, me encontrar, me moldar". Esta participante queria, com a educação superior, amadurecer, preparar-se para o trabalho, reconhecer-se, descobrir-se; por isso, fechou seu relato, dizendo que "a faculdade te abre horizontes que você não vai encontrar em outro lugar". A maior parte dos espaços abertos pela educação superior se situou no nível dos cursos realizados, indicando que a interação de professores e alunos, e entre estes, ainda é lugar privilegiado para a construção de experiências emancipadoras.

Contudo, prioritariamente, a presença mais significativa dessas experiências ocorreu na negação das participantes de alguns de seus valores e interesses. As críticas delas, com o abandono de posições valorizadas e de interesses definidos, mostraram-se elementos-chave na virada de rumos de suas vidas. Por este ângulo, mostrou-se significativo o relato de M4 o qual a expõe como uma pessoa que, antes da educação superior, era pouco habituada a refletir sobre si:

Eu era muito 'Maria-vai-com-as-outras', de concordar com a opinião dos outros. Eu pensava: 'Se a maioria pensa assim, então, é o correto'. Eu não tinha aquela coisa de pesquisa e saber se isso era realmente verdade. Uma professora questionava muito, 'se éramos cabeças pensantes ou se seguíamos o senso comum'. Antes de entrar na faculdade eu era muito senso comum e me baseava pela opinião dos outros; não tinha minha opinião própria, formada. Hoje consigo formar minha própria opinião, defendo ela sem desrespeitar os outros. A faculdade me deixou mais madura, mais de pensar e me deixou mais sensível pra questão social; de olhar o mundo de outra forma; porque eu sempre critiquei a questão política. Hoje não coloco a culpa dos problemas do Brasil somente nos políticos, mas na sociedade em si. A gente tem mania de colocar a culpa nos outros e não vê que a gente contribui para isso. O Brasil tá assim, mas eu também consigo me culpar [...] Eu tenho de ser mais; então, a faculdade me abriu esse olhar, ajudar o Brasil eu sendo diferente.

Nesse relato, assim como em outros, ficaram evidentes críticas normativas e cognitivas. Constata-se que a estudante deixa de valorizar o conformismo diante de problemas e, concomitantemente, passa a realizar análises - para em seguida tirar conclusões - de sua atitude de culpar os outros pelos problemas do país. Dada a limitação da pesquisa, ficou por descobrir percursos educativos que levaram essa participante a elaborar tais críticas. Contudo, está claro, pelo relato, que a instituição abriu espaços para que isso ocorresse. É, de fato, uma contraposição aos resultados de outra pesquisa (VASCONCELOS; GOMES, 2015), a qual constatou a mútua culpabilização pelo insucesso no ambiente acadêmico. 
A crítica normativa de M2 merece ser também exibida, alusiva à postura preconceituosa e exclusiva de pessoas neste mundo, paradoxalmente, entrecortado pelo discurso do respeito às diversidades:

Não sei se é por que sou brasileira, acho que não... deve ser o mundo inteiro. A pessoa, ela tem lá sua concepção de vida. E ela acha que aquilo é o certo. E o resto todo é errado. E ela não se dá ao menos a oportunidade de conhecer o outro; de conhecer o novo; de conhecer culturas novas; de saber da diversidade que existe no mundo.

A postura crítica, adotada pela participante, faz recordar o posicionamento teórico de Dussel (1995, p. 119) sobre a dinâmica por meio da qual as pessoas saem dos processos de opressão: "O projeto de libertação dos oprimidos e dos excluídos é aberto, partindo da exclusão do Outro e indo mais além [jenseits] de qualquer situação apresentada”. Em harmonia com o autor, as alternativas desse mais além não devem seguir modelos, idealismos, mundo da vida, lógicas, mas deverão constituir-se em descoberta como resposta à interpelação do Outro. Recorda ainda a explicação levinasiana sobre a alteridade, posto que, fundamentalmente, a estudante expõe a questão do diálogo em sua fala. Com efeito, para Lévinas (2010, p. 26-27), o ser humano é em si significação, palavra ética, o que remete à necessidade do diálogo entre as pessoas. Em busca do diálogo com o outro para além da linguagem, mantendo nesse diálogo a atitude aberta para recebê-lo enquanto significação, o sujeito que assim procede é capaz de deixar o outro ser como este é. Afirma o autor que, "por a existência de outrem, deixando-a ser, é já ter aceito essa existência, tê-la tomado em consideração”.

\section{Conclusão}

Qual a experiência de aprendizado favorável à emancipação de mulheres, em vinculação com outras experiências, aquelas originárias de sua condição social-cultural-econômica, em geral, denominada condição de vulnerabilidade? Qual a experiência de vida implícita na educação superior capaz de deixar livres essas mulheres para transgredirem o estado de embrutecimento, já definido como o uso da informação para renegar infinitos saberes das pessoas? Por ter sido um estudo de caso, esta pesquisa - esculpida com o material que constitui as mencionadas perguntas - se limita a deixar pistas e possibilidades de generalização pelos leitores, discorrida num texto que descreve experiências de superação convertidas em efetiva emancipação. Evidencia que tais mulheres, a exemplo de Hooks (2013, p. 12-13), em seu sonho realizado de transgressão, conseguem libertar-se do "conhecimento resumido à pura informação" e continuar acreditando que "a educação aumenta a nossa capacidade de ser livres".

Ao seu modo, elas aproveitam as oportunidades de emancipação oferecidas pela educação superior. Para verificar os pontos de encontro entre as experiências bemsucedidas e essas oportunidades, a pesquisa seguiu como no clamor ao albatroz, na histórica descrição daquele navio negreiro (HEINE; ALVES, [1868] 2009), pelo que os autores deste trabalho, igualmente ao poeta, se aproximaram da neurose contextual que abrange vítimas de violências e exclusões, frequentemente, deixadas ao relento da alienação. No presente trabalho, tais vítimas são mulheres esforçadas em suas comunidades de origem e que, depois ou durante, ingressam e permanecem na educação 
Ivar César Oliveira de Vasconcelos - Helen Tatiana dos Santos Lima - Ingrid Cristian da Silva Bezerra de Menez

superior, abrindo mais os olhos à realidade de um mundo dominado pela dispersão de sentidos.

Portanto, restam perguntas, cabendo aprofundar mais ainda o tema. $\mathrm{E}$ isto mesmo é a alma da educação, movida pela curiosidade e depois narrada em pesquisas. Pois, para que educar-se, senão para alargar o mundo à volta e, assim, banhar-se de perguntas e significados?

\section{Referências}

ADORNO, T. W. Educação e Emancipação. Tradução de Wolfgang Leo Maar. Rio de Janeiro: Paz e Terra, 1995.

BARDIN, L. Análise de conteúdo. 5. ed. Lisboa: Edições 70, Lda., 2009.

BELL, D. O advento da sociedade pós-industrial. São Paulo: Cultrix, 1974.

BERTAUX, D. Los relatos de vida: perspectiva etnosociológica. Barcelona: Ediciones Bellaterra, 2005.

BLAY, E. A; CONCEIÇÃO, R. A mulher como tema nas disciplinas da USP. Cadernos de Pesquisa, n. 76, p. 50-56,1991.

BOURDIEU, P.; CHAMPAGNE, P. Os excluídos do interior. In: NOGUEIRA, M. A; CATANI, A. (Orgs.). Pierre Bourdieu: escritos de educação. 16. ed. Petrópolis: Vozes, 2015. p. 243-255.

BRASIL. Decreto 8.136/2013, de 5 de novembro de 2013. Aprova o regulamento do Sistema Nacional de Promoção da Igualdade Racial... Brasília: Casa Civil, 2013a. Disponível em: <http://www.planalto.gov.br/ccivil_03/_ato2011-2014/2013/decreto/d8136.htm>. Acesso em: 5 dez. 2017.

BRASIL. Lei $\mathbf{n}^{\circ}$. 11.340, de 7 de agosto de 2006. Cria mecanismos para coibir a violência... Brasília: Casa Civil, 2006. Disponível em: < http://www.planalto.gov.br/ccivil_03/_ato20042006/2006/lei/111340.htm>. Acesso em: 5 dez. 2017.

BRASIL. Lei $\mathbf{n}^{\circ}$ 12.288, de 20 de julho de 2010. Institui o Estatuto da Igualdade Racial... Brasília: Casa Civil, 2010. Disponível em: < http://www.planalto.gov.br/ccivil_03/_ato20072010/2010/lei/112288.htm>. Acesso em: 5 dez. 2017.

BRASIL. Lei $\mathbf{n}^{\mathbf{0}}$. 12.852, de 5 de agosto de 2013. Institui o Estatuto da Juventude e dispõe sobre os direitos dos jovens, os princípios e diretrizes das políticas públicas de juventude e o Sistema Nacional de Juventude - SINAJUVE. Brasília: Casa Civil, 2013b. Disponível em: <http://www.planalto.gov.br/ccivil_03/_Ato2011-2014/2013/Lei/L12852.htm>. Acesso em: 5 dez. 2017.

BRESCIANI. M. S. M. O Anjo da Casa. História e Perspectiva, Uberlândia, v. 7, p. 191-223, 1992.

CARDOSO, R. (Org.). A aventura antropológica: teoria e pesquisa. 4. ed. São Paulo: Editora Paz e Terra, 2004.

CORALINA, C. Poemas dos becos de Goiás e estórias mais. 23. ed. São Paulo: Global, 2014.

DAMATTA, R. O que é o Brasil? Rio de Janeiro: Rocco, 2004.

DE GAULEJAC, V. Les sources de la honte. Paris: Desclée de Brouwer, 2008.

DUBET, F. Sociologia da experiência. Lisboa: Instituto Piaget, 1994.

DUSSEL, E. Filosofia da libertação: crítica à ideologia da exclusão. São Paulo: Paulus, 1995. 
FREIRE, P. Pedagogia da indignação: cartas pedagógicas e outros escritos. 3. ed. São Paulo: Paz e Terra, 2016.

FREITAG, B. O indivíduo em formação: diálogos interdisciplinares sobre a educação. 3. ed. São Paulo: Cortez, 2001.

HAHNER, J. E. Emancipação do sexo feminino: a luta pelos direitos da mulher no Brasil, 1850-1940. Florianópolis: Ed. Mulheres, 2003.

HEINE, H.; ALVES, C. Navios negreiros. São Paulo: Comboio de Corda, 2009.

HONORATO, G.; HERINGER, R. (Orgs.) Acesso e sucesso no ensino superior: uma sociologia dos estudantes. Rio de Janeiro: 7Letras: FAPERJ, 2015.

HOOKS, B. Ensinando a transgredir: a educação como prática da liberdade. São Paulo: Editora WMF Martins Fontes, 2013.

INSTITUTO BRASILEIRO DR GEOGRAFIA E ESTATÍSTICA (IBGE). Perfil das mulheres responsáveis pelo domicílio no Brasil. Disponível em: <https://biblioteca.ibge.gov.br/ pt/biblioteca-catalogo?view=detalhes\&id=281814>. Acesso em: 5 dez. 2017.

JAEGER, W. W. Paideia: a formação do homem grego. 4. ed. São Paulo: Martins Fontes, 2001. LÉVINAS, E. Entre nós: ensaios sobre a alteridade. 5. ed. Petrópolis: Vozes, 2010.

MERRIAM, S. B. Qualitative research and case study applications in education. São Francisco: Jossey-Bass Publishers, 1998.

LIRA, A. Indisciplina e violências: como alunos adolescentes veem seus professores. 2016. 299 f. Tese (Doutorado em educação) - Universidade Católica de Brasília, Brasília, 2016. Disponível em: <https://bdtd.ucb.br:8443/jspui/bitstream/tede/2108/2/AdrianaLiraTese2016.pdf>. Acesso em: 9 mar. 2018.

MORAIS, R. Um abominável mundo novo?: o ensino superior atual. São Paulo: Paulus, 2011.

OLIVEIRA, A. R.; OLIVEIRA, N. (Orgs.). Exclusão: um olhar para além da aparência. Chapecó: Argos, 2016.

ORGANIZAÇÃO DAS NAÇÕES UNIDAS (ONU). Word population prospects: the 2017 revision: key findings and advance tables. New York: United Nations, 2017.

PINTO, E. J. S.; CARVALHO, M. E. P.; RABAY, G. Gênero: um fator condicionante nas escolhas de cursos superiores. In: REDOR, 18, 2014, Recife. Anais... Recife: UFRP, 2014. p. 233-249.

QUEIROZ, D. M. Mulheres no ensino superior no Brasil. In: 23a Reunião Anual da Associação Nacional de Pesquisa e Pós-Graduação em Educação. Rio de Janeiro: ANPED; Caxambu: Caderno de resumos, 2000.

ROMANELLI, O. O. História da educação no Brasil (1930/1973). Petrópolis: Editora Vozes, 2003.

ROUSSEAU, J-J. Emílio ou da educação. São Paulo: Edipro, [1762], 2017.

STAKE, R. A arte da investigação com estudos de caso. 4. ed. Lisboa: Fundação Calouste Gulbenkian, 2016.

STAVRACAS, I.; ESTEBAN ROJO, R. Considerações acerca da emancipação da educação e da música em Theodor W. Adorno. In: Vercelli, Ligia (Org.). Educação não formal: campos de atuação. Jundiaí: Paco Editorial, 2013. p. 163-176.

TAVARES, J. Uma sociedade que aprende e se desenvolve: relações interpessoais. Porto: Ed. Porto, 1996. 
Ivar César Oliveira de Vasconcelos - Helen Tatiana dos Santos Lima - Ingrid Cristian da Silva Bezerra de Menez

TEIXEIRA, A. S. Educação no Brasil. 2. ed. São Paulo: Ed. Nacional; Brasília: INL, 1976.

UNIÃO INTERNACIONAL DAS TELECOMUNICAÇÕES (UIT). ICT facts and figures 2017. Genebra: ONU, 2017. Disponível em: <https://www.itu.int/en/ITU-D/Statistics/ Documents/facts/ICTFactsFigures2017.pdf >. Acesso em: 5 dez. 2017.

UNITED NATIONS POPULATION FUND (UNFPA). Motherhood in Childhood: facing the challenge of adolescent pregnancy. New York: UNFPA, 2013.

UNITED NATIONS POPULATION FUND (UNFPA). Millions of lives transformed. New York: UNFPA, 2016. Disponível em: <http://www.unfpa.org/sites/default/files/pub-pdf/ Annual-Report-2016.pdf>. Acesso em: 5 dez. 2017.

XIBERRAS, M. As teorias da exclusão: para uma construção do imaginário do desvio. Lisboa: Instituto Piaget, $\mathrm{s} / \mathrm{d}$.

VASCONCELOS, I. C. O. In: A participação dos jovens em redes sociais virtuais: aspectos de uma experiência social. SOUSA: Juventudes e tecnologias: sociabilidades e aprendizagens. Brasília: Liber Livro, 2015. p. 81-100.

VASCONCELOS, I. C. O. Estudo de caso interativo: fácil entender, decidir e executar. Curitiba: CRV, 2017.

VASCONCELOS, I. C. O.; GOMES, C. A. C. Jovens estudantes universitários e seus professores em interação social. Atos de pesquisa em educação, Blumenau, v. 10, n. 2, p. 605-629, 2015. Disponível em: <http://proxy.furb.br/ojs/index.php/atosdepesquisa/article/view/4316>. Acesso em: 05 dez. 2017.

YIN, R. K. Estudo de caso: planejamento e métodos. 4. ed. Porto Alegre: Bookman, 2010.

* Professor doutor da Universidade Católica de Brasília, Brasília, Distrito Federal, Brasil.

** Doutoranda em Educação pela Universidade Católica de Brasília, Brasília, Distrito Federal, Brasil.

*** Mestranda em Educação pela Universidade Católica de Brasília, Brasília, Distrito Federal, Brasil.

\section{Correspondência}

Ivar César Oliveira de Vasconcelos - Universidade Paulista DF, Campus Brasília. SGAS 913, s/n - Conjunto B, Asa Sul. CEP: 70390130. Brasília, Distrito Federal, Brasil.

E-mail: ivcov@hotmail.com - helenlima.psi@gmail.com - ingridcristian@bol.com.br

Aprovado em 09 de março de 2018 